\title{
Research on the Reform and Innovation of Teaching Methods of Local Comprehensive Universities
}

\author{
MA Xiao-jun \\ College Mechanical Engineering \\ Jiamusi University \\ Jiamusi, China \\ mjzx2009phd@163.com
}

\author{
$\mathrm{LI} \mathrm{Mu}$ \\ School of Finance and Business \\ Shanghai, China
}

\author{
LI Chun-jiang* \\ Academic Affairs \\ Jiamusi University \\ Jiamusi, China \\ jmslcj@sohu.com
}

\begin{abstract}
The reform and innovation of teaching methods in improving the quality of education play a vital role in higher education must be based on the teaching of advanced ideas and theories as a guide. Therefore, it is necessary to education and innovative teaching methods, principles, concepts, and objectives and characteristics, especially on "capacity- building - Evaluation - oriented" teaching the meaning and practical significance to be explored.
\end{abstract}

Keywords-Local Comprehensive Universities;teaching reform; teaching Innovation; capacity building

\section{INTRODUCTION}

Higher education to train to adapt to production, construction, management and service the needs of first-line advanced technology talents as a fundamental task, the teaching model and methods in improving the quality of education and educational characteristics of the formation of an extremely important role. Looking at China's reform of education teaching methods, mainly the following problems: First, theoretical research lag. Teaching methods of the theory of education studies have not been fully appreciated, there is no theoretical research breakthrough innovation in teaching methods, there would be no changes in the reform of education will become castles in the air. Second, the teaching ideas are old hat. At present the theory is still subject-oriented, to teach academic theory as the main task of education to the educated to accept the extent of theoretical knowledge to measure the effectiveness of teaching. Merely treat the students as an educational object, do not see the main body of teaching students is the ability of the active construction of knowledge who do not understand the intelligence structure and type of

Reform project of Heilongjiang Province: (JG2014011046), Jiamusi University teaching research project (2016JW1009), Jiamusi University degree and postgraduate education teaching reform project (JGXM-JDY2016011)and Heilongjiang institute of higher education project(16G206)

*Corresponding author:LI Chun-jiang, jmslcj@sohu.com students the difference between the development of students focus on the integration requirements and standards, neglect their personality and expertise to the mining culture. Third, practical application obsolete. Emphasis in teaching knowledge, systematic and thorough, requiring of know these, but also know why they are accustomed to, "Man Tang guan "knowledge transfer methods, lack of teachers and students, between the multi-directional communication among students, emphasis on book knowledge, ignore the practical training, leading to a lack of trained students employ ability, can not meet the needs of the market.

\section{HIGHER EDUCATION AND THE PRINCIPLES OF INNOVATION IN TEACHING METHOD}

Any kind of innovation and advanced the theory must be supported. Innovation in teaching methods of higher education should grasp the following principles: First, innovation in education should be the basis of modern theory and psychological theory, and based on the overall reform of education and teaching background; Second is an innovative education according to the teaching of uniqueness, and build on the framework of education among the teaching model; third is to rely on science and technology innovation and development, and established in the modern educational technology platform.

Since the 20th century, with modem education, psychology and the development of constructivist learning theory, the main education and cooperative learning theory, multiple intelligence theory, the theory of lifelong education, quality education, theories of the far-reaching reform of education and teaching, which affect the There are a large number of fundamental point: 


\section{A. Knowledge is not to be taught by teachers}

Knowledge is not to be taught by teachers, but learners in certain contexts that the social and cultural context, with the help of other people (including teachers and learning partners) to help with the necessary learning materials, through the construction of meaning.

\section{B. To recognize and respect for the students in the educational activities of the dominant position}

To recognize and respect for the students in the educational activities of the dominant position, through cooperative learning and teacher-student interaction, in harmony to create a positive thinking, to explore the atmosphere, so that students quickly acquire knowledge and skills, thus giving birth to innovative thinking, practical personnel.

\section{Human intelligence types and smart structure is different}

Human intelligence types and smart structure is different, different types of smart structures and intelligent grasp of the knowledge people have different directivity. While students in colleges linguistic intelligence and mathematical logic, intelligence in general less than the average college students, but in sports intelligence, spatial intelligence, has been more prominent in the hands-on grasp of the skills that have comparative advantages, education must be concerned about this kinds of differences, we should fully tap the potential of students, and strive to avoid weaknesses.

\section{Higher education is not the end of sex education}

Higher education is not the end of sex education, but a lifelong education, a stage, so the students can not be limited to career abilities, but to pay attention to the continuous development of their professional capabilities, for the educated lay the foundation for lifelong learning.

\section{E. Education is a quality education}

education is a quality education, not only to impart knowledge and skills of students, but also should focus on personality development of students, professional capacity, innovation and entrepreneurial spirit and ability to fully develop, to teach students how to life, how to learn and how to develop.

\section{F. Higher education is a capacity to develop comprehensive education}

Higher education is a capacity to develop comprehensive education, integrated capabilities include professional competence, method competence and social competence with a specific, specialized knowledge and skills have no direct contact is a can migrate across positions, inter-professional working capacity.

The view is that innovation in teaching methods, education, and the basic idea. This as a support, education, innovative teaching methods should follow the following basic ideas:
- The emphasis on practice and application, pay attention to coordinated development;

- Emphasize the development of smart students;

- So that students and teachers the enthusiasm of the leading the role of the effective integration;

- Research and guide the students learning methods;

- Emphasis on the cultivation of non-intelligence factors of students;

- Note the diversity of intelligence, so that individualized. The goal of innovation to achieve the six "benefits", that is conducive to the formation of student's comprehensive ability, is conducive to students sense of innovation and creativity, and promoting the personality development of students, to students a comprehensive quality, will help improve student learning capacity that will benefit students in the cultivation of nonintelligence factors.

\section{HIGHER EDUCATION AND THE BASIC REQUIREMENTS FOR INNOVATIVE TEACHING METHODS}

Practical with other types of stress, level of education compared with education, a greater emphasis on practical teaching methods, this is a feature of education and teaching, and also develop technical skills talents basic guarantee. Practical teaching methods are mainly embodied in the following aspects: First, interactive, attention to student participation, to develop student's ability. Second, adhere to the practice-oriented apply their knowledge to enhance students professional skills development. Third, the academic and employment, entrepreneurship closely, pays attention to the cultivation of professional quality, and strives to enable students to obtain employment through practical teaching skills and entrepreneurial ability.

Teaching methods reflect the nature of the innovation must be in teaching the form, content, goals, teacher role, the methods of participation, incentives, quality control and so different from the traditional teaching methods, one prominent in the guiding ideology inspiring and student initiative, and second, the starting point of the reform of modern professional ability to highlight the training and the third is the goal of innovation emphasized that teach students to learn, four are the means of great importance in the teaching of modern advanced technology.

Highlight the learning of some foreign countries and regions of higher education teaching models and methods, such as Germany' s "dual system" Canada, the United States to competency-based CBE (Competency Based Education) training model, the United Kingdom, Australia, CompetencyBased (CBET) training model, are proved to be effective approach, although limited by cultural traditions, can not be completely copied, but its advanced teaching ideas and operational methods of some of our innovative teaching methods, higher colleges are still has a good reference value and learn. 
Promoting diversity from higher education is a multi-factor, multi-disciplinary, multi-standard, multi-type of a complex educational system, and with the economic sector, labor market have a direct link, involving different industries and different professions, the various professional needs of operational skills, mental skills, have different characteristics, thus requiring a variety of teaching methods corresponding operational. Teachers in teaching according to different situations and adopt flexible teaching methods to meet the complex and diverse teaching situations, as much as possible to meet the diverse learning needs of students. Reposted else where in the paper for free download. "Capacity Building - evaluation-oriented" Exploration and Practice of Teaching

In view of teaching in skills, teaching status, should apply to skills in teaching specialized courses "Capacity Building evaluation-oriented" teaching methods were discussed. "Capacity Building - Evaluation-oriented" pedagogy of the socalled "capacity building-Evaluation-oriented" teaching method is based on an analysis of professional competence to determine the students should have the knowledge, skills, goals, through the active involvement of students, teachers guidance, to enable students to take the initiative to build knowledge structure, and ability to structure and character structure, and quality objectives and process evaluation to guide students, inspired by active learning teaching methods. Its operating procedures can be summarized as talks, demonstrations, design, simulation, evaluation of five areas:

- Explain. Is through the language describe, analyze and reveal the skills constitute the theoretical basis of the objectives and skill standards, to enable students to better grasp the inherent skills. Mainly uses the inductive method and deductive method, through the narrative, explanation, analysis, summarized in the form, highlight the skill points, closely linked to the ability goals, inspire students to think, and with a variety of instructional media to mobilize the thinking of the students enthusiasm and initiative.

- Demo. Is the image display of skills in action in whole or in Part, so that students are familiar with things in the shape, structure and change process, in order to acquire these skills lay the foundation. Demonstration can be carried out by teachers, but also by video or enable outstanding students.

- Design. Is through cognitive and emotional factors play a role in the formation of skills, will rely on a simple analog into intelligence, better skills training and the speed and efficiency. Ask students to refer to examples constitute the training procedures in the mind, a combination of movements to grasp, seize the key skills to form a technique. The complex mix of skills, you can pre-design drawings or programs so that simulation is more accurate and innovative.

- Analog. Is a program formed in accordance with the mind to practice, to enable students experience the essentials skills to operate. In the training can be a means to introduce micro-teaching, teachers to use onsite filming of the video, observe and correct Student movements, effectively improve the quality of skills training.

- Evaluation. Is the feedback control objectives should be to avoid the randomness and generalized preaching, pay attention to mobilizing students to self-involved to ensure that evaluation of more focused, certainty and scope.

\section{THE ABILITY TO BUILD THE THEORETICAL SIGNIFICANCE OF TEACHING MODEL}

The ability to build the theoretical significance of teaching model based on professional competence as the basis and allround human development as the goal, while seeking to teaching in the classroom structure, teaching methods combined model, with modern teaching media breakthrough, through the ways and means of optimization, and ultimately achieving the purpose of improving teaching quality. Its theoretical significance lies in:

- Course from development mode to the reform of teaching mode, handling skills and knowledge, skills and abilities, the main and dominant, the relationship between goals and results, the application CBE professional competence and professional skills of objective design analysis methods, to develop of teaching and learning objectives, to seize the practical skills of teaching, students subjectivity, objective striking feature of such a comprehensive, reflecting the ability to foster the principles of the main line.

- Is based on cognitive psychology, education, and law, teaching methods, information on who should carry out an orderly process to strengthen awareness, according to a psychological point of view, learning motivation, interest in learning, learning motivation, and cognitive processing characteristics of a series of factors that affect the learning control.

- The teaching is based on the demo - analog, but for different forms of organization and teaching content, you must be extended with the combination of materials to learn the contents of the carrier, the shanih is a bridge between cognitive activities of shariah model research should reflect the diversity as well as the combination of dynamic and static.

- Teaching pattern reflects the diversity of thought can use as applicable to all types of specialized courses teaching practical teaching methods.

- Better reflects the integrity of instructional design principles, the main principles of the learning process as well as practical skills in the principles of operation. In the instructional design and teaching the use of the media, we should extensive use of multimedia teaching techniques, taking into account the modem teaching design ideas, the active participation of students of students immediate feedback, teach students learning to master these three points as a key consideration. 
The ability to build the practice of teaching the value of (1)can stimulate teachers and students in bilateral activities in the enthusiasm and initiative, so that classroom teachers and students to become close cooperation, coordination interaction, work together to build the activities of the main process.(2)increase training density, improve training efficiency, and achieving Jingling more practice. (3)comprehensive ability for students to professional formation, can form a general learning ability, but also includes the formation of co-consciousness and the spirit of innovation, including professional comprehensive ability. (4)The ability to build models for various levels of technical training requirements. (5)can play in enhancing the quality Of teachers, guidance and incentives, capacity building training the teaching model is based on professional competence as the core, and therefore, teachers should first have the coaching skills.

\section{CONCLUSION}

After a long period of comparative neglect teaching methods in higher education are now becoming the subject considerable research interest in China. Arguments for and against lecturing and the claims of the seminar and tutorial to a greater share of time are being debated by both students and staff in junior and senior common rooms. Opinion in general seems to be coming out in favor of more seminars and tutorials and less lecturing. However, the ability to build the theoretical significance of teaching model based on professional competence as the basis and all-round human development as the goal, while seeking to teaching in the classroom structure, teaching methods combined model, with modern teaching media breakthrough, through the ways and means of optimization, and ultimately achieving the purpose of improving teaching quality.

\section{ACKNOWLEDGMENT}

The authors would like to thank financial support by the project of the Reform project of Heilongjiang Province: (JG2014011046), Jiamusi University teaching research project (2016JW1009), Jiamusi University degree and postgraduate education teaching reform project (JGXM-JDY-2016011) and Heilongjiang institute of higher education project (16G206).

\section{REFERENCES}

[1] Li Chunying. The Study of Children's English Teaching Methods-Based on the Characteristics of Children's Cognitive Development[A]. International Informatization and Engineering Associations,Atlantis Press.Proceedings of International Conference on Education Technology and Social Science[C].International Informatization and Engineering Associations,Atlantis Press:,2014:3.

[2] Zhi-Wei ZONG. Comparative Study on PTR Teaching Method and Traditional Teaching Method in Skill Study of University Students -A Case Study of Tennis Elective Course in Shanghai University[A]. The Chinese Athletics Association of Universities and Colleges.Proceedings of the Xi'an 2012 International Conference of Sport Science \& Physical Education Volume III :Physical Education and Health[C].The Chinese Athletics Association of Universities and Colleges:,2012:4.

[3] Luo Aiming. Empirical Research on Task-based Teaching Method in Vocational College Nursing English Teaching[A]. International Informatization and Engineering Associations,Atlantis Press.Proceedings of 2013 2nd International Conference on Management Science and Industrial Engineering(MSIE 2013)[C].International Informatization and Engineering
Associations,Atlantis Press:,2013:4.

[4] Zhang Wei. The Application Exploration of Lexical Chunks Teaching Method in College English Writing Driven by Language Consciousness[A]. Xiamen University,Sanya University.Proceedings of 2nd International Conference on Social Science and Higher Education(ICSSHE $2016 \quad$ V53)[C].Xiamen University,Sanya University:,2016:4.

[5] Xu Yiqun. Application of Interaction Teaching Method in College English Listening Teaching[A]. Xiamen University,Sanya University.Proceedings of 2nd International Conference on Social Science and Higher Education(ICSSHE 2016 V53)[C].Xiamen University,Sanya University:,2016:4.

[6] Lanxin Hu. Exploration Teaching Method of "Communication Engineering" Technical Talents[A]. Xiamen University,Sanya University.Proceedings of 2nd International Conference on Social Science and Higher Education(ICSSHE 2016 V53)[C].Xiamen University,Sanya University:,2016:5.

[7] Jin Zhang Tianjin University of Traditional Chinese Medicine,Tianjin 300193. Comparison and Analysis on the Effects of PBL Teaching Method and the Traditional Teaching Method[A]. Information Engineering Research Institute,USA.Lecture Notes in Information Technology-Proceedings of 2012 International Conference on Education Technology and Management Engineering(ETME 2012)[C].Information Engineering Research Institute,USA:,2012:4.

[8] Qianni Luo,Yuqing Yang. Application of Task-based Language Teaching Method in Teaching Extensive English Reading[A]. Information Engineering Research Institute,USA.Proceedings of 2013 the Fourth International Conference on Information,Communication and Education Application(ICEA 2013) Volume 30[C].Information Engineering Research Institute,USA:,2013:5.

[9] Lin Gao. The General Education of Consumer Psychology the Teaching Method[A]. Information Engineering Research Institute, USA.Proceedings of 2015 the 5th International Conference on Information,Communication and Education Application(ICEA 2015)[C].Information Engineering Research Institute, USA:,2015:5.

[10] WANG Xinhuan 1 , ZHOU Fei 2 , ZHANG Hongwei 11 School of Electrical Engineering \& Automation 2 Modern educational technology center Henan Polytechnic University Jiaozuo, China. The Research and Practice of Teaching Method Reform for Single-chip Microcomputer Course[A]. IACSIT-International Association of Computer Science and Information Technology).Proceedings of 2012 4th International Conference on Education Technology and Computer(ICETC 2012)[C]. IACSIT-International Association of Computer Science and Information Technology):,2012:5.J. Clerk Maxwell, A Treatise on Electricity and Magnetism, 3rd ed., vol. 2. Oxford: Clarendon, 1892, pp.68-73. 